\title{
The American frontier: Technology versus immigration ${ }^{\text {th }}$
}

\author{
Guillaume Vandenbroucke \\ Department of Economics, University of Southern California, 3620 S. Vermont Ave., KAP 324F, Los Angeles, CA 90089-0253, USA
}

Received 22 May 2006; revised 30 June 2007

Available online 11 August 2007

\begin{abstract}
How important was international immigration for the US and its demography during the nineteenth century? This paper investigates, quantitatively, its effect on the westward movement of population and the regional and secular changes in fertility. Beside immigration, two alternative forces are considered: technological progress and the land policy (the Homestead Act). An optimal growth model with endogenous fertility and migration is calibrated, and counterfactual experiments reveal that the main driving forces were productivity growth and the declining cost of transportation. International immigration played a lesser role.
\end{abstract}

(c) 2007 Elsevier Inc. All rights reserved.

JEL classification: $\mathrm{E} 1 ; \mathrm{J} 1 ; \mathrm{O} 1$

Keywords: Population growth; Migration; Fertility; Technological progress; US westward expansion

\section{Introduction}

The United States is often viewed as a "country of immigrants." The fact is that, during the nineteenth century, the rate of international immigration averaged five percent per decade, accounting from seven percent of the rate of population growth during the 1820 s to $33 \%$ during the 1850s. ${ }^{1}$ Panel A of Fig. 1 shows the decomposition of the growth rate of population, and the contributions of the rates of net migration and natural increase. Panel B proposes a simple exercise to assess the importance of international immigration. It shows the US population vis à vis the path that would have occurred if population grew at its rate of natural increase. The result is remarkable: without international immigration, the US population in 1900 would have been $52 \%$ below its actual value. This exercise suggests that immigration mattered, but it assumes that the rate of natural increase was no affected by immigrants. This paper proposes to relax this assumption and to use the optimal growth model to study the key patterns of the US demography during the nineteenth century. The objective is to measure the impact of immigration versus alternative driving forces, such as various aspects of technological progress, and the land policy set by the US government-that is the mechanism through which the government attempted to regulate the settlement of the western territories.

\footnotetext{
This is a revised version of the third chapter of my dissertation submitted to the University of Rochester, and previously circulated under the title "The American Frontier: One Hundred Years of Western Settlement."

E-mail address: vandenbr@usc.edu.

1 See Haines (2000, Table 4.1).
} 


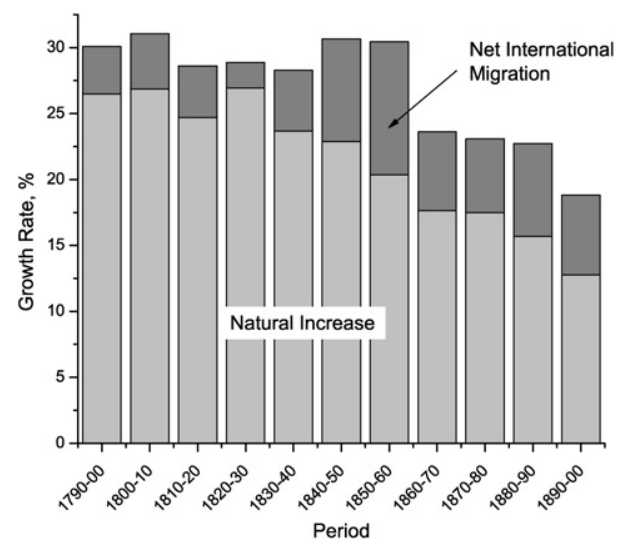

(A)

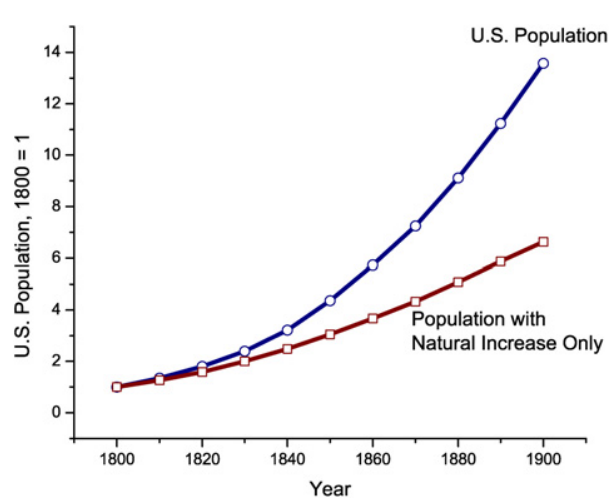

(B)

The source of data is Haines (2000, Table 4.1). Panel A represents the growth rate of total population, per decade, and its decomposition between natural increase and net migration. This decomposition is based on the following accounting equation, where $p_{t}$ represents total population:

$$
\frac{p_{t+1}-p_{t}}{p_{t}}=\frac{\# \text { births }_{t}-\# \text { deaths }_{t}}{p_{t}}+\frac{\text { \#immigrants }_{t}-{\text { \# } \text { outmigrants }_{t}}_{t}}{p_{t}} .
$$

The first element on the right-hand side is the rate of natural increase and the second element is the rate of net migration. Panel B represents the level of population, normalized to one in 1800 , and the path that the rate of natural increase alone would have implied.

Fig. 1. Population Growth in the United States, 1800-1900.

The paper proceeds as follows. The rest of this section presents the main facts of interest and discusses potential explanations. In particular, Section 1.1 documents the trends in regional fertility and the geographic distribution of population. Section 1.2 hypothesizes that technological progress, in various activities, can be an alternative to international immigration in generating these trends. Section 2 presents the model and Section 3 the quantitative analysis. The latter consists first in matching the model to the US data and, then, running a set of counterfactual experiments to assess the quantitative importance of each exogenous force built into the model. The conclusion of this exercise is that immigration had a "smaller-than-expected" impact on the US demography, while transportation costs and wage growth mattered significantly. Specifically, one experiment shows that international immigration directly affected the rate of population growth, but hardly affected the rate of natural increase and the geographic distribution of population. Another experiment shows that technological progress in transportation and in the production of goods drove most of the geographic distribution of population. Finally, the paper considers two land policies. The baseline policy is reminiscent of the Homestead Act, i.e., when the US government gave the land out to those who settled it without titles. The alternative policy is reminiscent of the auction mechanism often used to sell acres of western land to the public. Interestingly, the two policies led to very similar results in terms of western settlement. However, they affected the rate of natural increase differently: under the Homestead Act, population growth was slower than when the government sold the land. Section 4 presents some concluding remarks.

\subsection{Facts}

What were the key patterns of the US demography during the nineteenth century? First, there was international immigration as mentioned above. It is interesting to know that immigrants settled in all regions of the country. As Table 1 shows, the proportion of foreigners rose both in the East and the West between 1820 and 1860 .

In addition to high rates of net migration, the US demography was also characterized by high rates of natural increase compared with the rest of the world. At a more disaggregated level, there were sharp regional differences. In particular, the rate of population growth in the West was higher than in the East, as illustrated by the changing geographic distribution of population in Fig. 2- the source of data is Mitchell (1998, Table A.3). This phenomenon, often referred to as the "Westward Expansion," shaped the US as we know it today. By the end of the nineteenth century the rates of population growth in each region have converged, and the geographic distribution of population became stationary. 
Table 1

Percent of Foreign Born per Region, 1820 and 1860

\begin{tabular}{|c|c|c|c|c|c|}
\hline & 1820 & 1860 & & 1820 & 1860 \\
\hline New England & & & Middle Atlantic & & \\
\hline Maine & 0.57 & 6.00 & New York & 1.13 & 26.10 \\
\hline New Hampshire & 0.05 & 6.40 & New Jersey & 0.59 & 19.00 \\
\hline Vermont & 0.40 & 10.40 & Pennsylvania & 1.05 & 15.10 \\
\hline Massachusetts & 0.66 & 22.20 & & & \\
\hline Rhode Island & 0.30 & 21.90 & & & \\
\hline Connecticut & 0.21 & 17.90 & & & \\
\hline East North Central & & & West North Central & & \\
\hline Ohio & 0.61 & 14.20 & Minnesota & - & 34.70 \\
\hline Indiana & 0.57 & 8.80 & Iowa & - & 15.70 \\
\hline Illinois & 1.11 & 19.00 & Missouri & 0.89 & 15.10 \\
\hline Michigan & 7.63 & 20.30 & Dakota & - & 68.90 \\
\hline Wisconsin & - & 35.80 & Nebraska & - & 22.10 \\
\hline & & & Kansas & - & 11.90 \\
\hline
\end{tabular}

The source of data is Yasuba (1962, Table V-17).

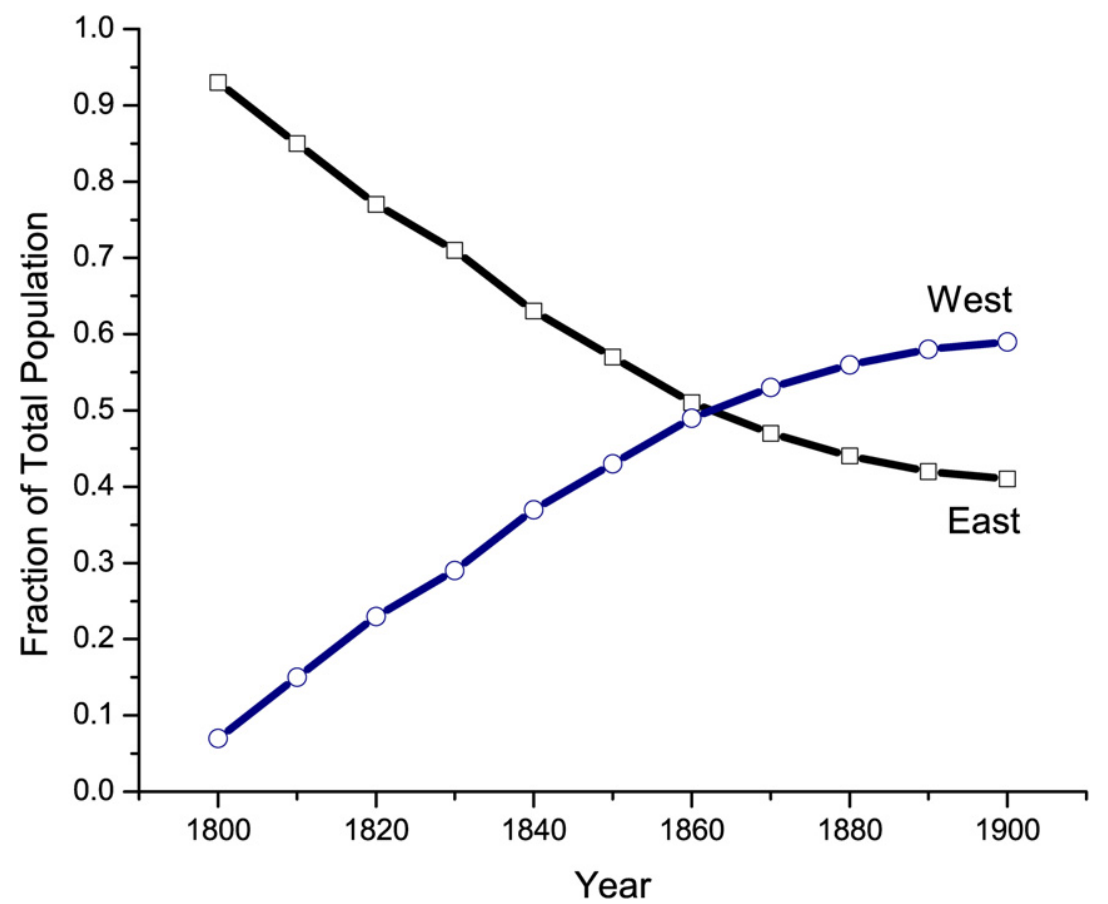

The "East" is arbitrarily defined as the New-England, Middle-Atlantic and South Atlantic regions. The list of states in these regions are Maine, New Hampshire, Vermont, Massachusetts, Rhode Island, Connecticut, New York, New Jersey, Pennsylvania, Delaware, Maryland, District of Columbia, Virginia, West Virginia, North Carolina, South Carolina, Georgia and Florida. The West consists of all other states in the continental US.

Fig. 2. Regional shares of total population, US, 1790-1910.

The faster population growth experienced by the West was due, at the same time, to high rates of net migration and natural increase relative to the East. To illustrate the importance of western migration, consider the East North Central states: Ohio, Indiana, Illinois, Michigan and Wisconsin. ${ }^{2}$ During the early stages of the century this region was the western Frontier of the country, and Fig. 3 shows the decomposition of the growth rate of its population-the source of data is Gallaway and Vedder (1975, Table 1). Net migration accounted for more than $80 \%$ of population growth

\footnotetext{
2 Similar data are not available for the entire century because the US census did not systematically collect data on population by state of birth and state of residence before 1850 .
} 


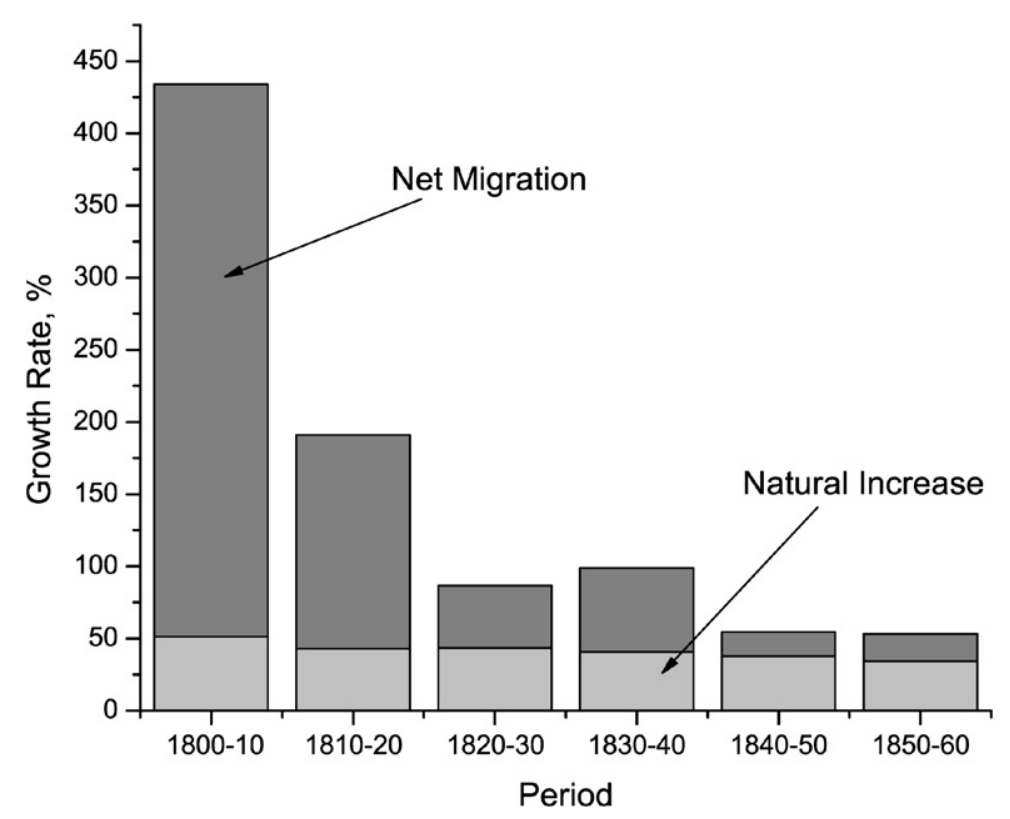

Fig. 3. The rate of population growth in the East North Central States, 1800-1860.

during the years 1800-1810, and more than 70\% during the next decade. As time passed its contribution declined, however, because the region was not on the Frontier anymore and more western areas attracted settlers.

The rest of western population growth derived from natural increase, which was higher than in areas of older settlement. Table 2 reports the refined birth ratios - the number of children under 10 years of age per women aged 16 to 44 - by states, for the period $1800-1860 .^{3}$ In 1800 , for example, a white woman in Ohio had 2.5 children under 10 years of age, vis à vis 1.4 in Massachusetts. The general pattern transpiring from Table 2 is that the birth ratio was higher in the West compared to the East, and in the South compared to the North. Observe also the tendency of birth ratios to decline. This was not specific to the US economy, and has been largely documented. Haines (2000, Table 4.3), for example, reports a 50\% decrease in the birth ratio (49\% for the fertility rate) for the entire United States over the period 1800-1900.

At this stage, it is important to mention another set of facts closely related to the US demography of this period. Specifically, Easterlin (1976) shows that when most of the land in a given state was farmed, out-migration started and the state's demography became driven mostly by natural increase. Gallman $(1992,2000)$ emphasizes the importance of land-improvement activities. The large areas of land-the stock of improved land was multiplied by a factor of about 16 between 1800 and 1900 — in the West were no free lunch. In order to settle in an area, pioneers had to improve the land which, before that, was not suitable for production purposes. Investment in productive land and the process of settlement are, therefore, closely related. Primack (1962) shows that there has been noticeable productivity gains in land-improvement activities such as clearing, breaking, irrigating, draining and fencing.

\subsection{Discussion}

What are the forces that can account for the key patterns of population growth in the US during the nineteenth century? This paper considers international immigration as an exogenous force, and asks how it may have contributed to the demographic trends just described. But other exogenous variables are also under consideration, such as pro-

\footnotetext{
3 The birth ratio is not a direct measure of fertility. If a fertile woman has $n$ births per year, the fertility rate is $n$. If $90 \%$ of children survive to age 10, the birth ratio associated with a constant fertility $n$ becomes $9 n$. But fertility is not constant, it declines. Thus, the birth ratio associated with a contemporaneous fertility rate $n$ is greater than $9 n$. Specifically, the current cohort of children aged 0 to 1 , determined by current fertility, is of size $n$ while older cohorts are of size greater than $n$. It is important to keep in mind that the birth ratio, or any measure of fertility, does not capture the rate of natural increase perfectly. Ideally, one should take into account differences in mortality and in the male/female ratio.
} 
Table 2

Number of children under 10 years of age per 1000 women aged 16-44, US, 1800-1860

\begin{tabular}{|c|c|c|c|c|c|c|c|}
\hline & 1800 & 1810 & 1820 & 1830 & 1840 & 1850 & 1860 \\
\hline & \multicolumn{7}{|c|}{ New England } \\
\hline Maine & 1974 & 1883 & 1621 & 1463 & 1416 & 1217 & 1108 \\
\hline New Hampshire & 1704 & 1558 & 1385 & 1207 & 1112 & 915 & 900 \\
\hline Vermont & 2068 & 1788 & 1468 & 1341 & 1286 & 1131 & 1079 \\
\hline Massachusetts & 1477 & 1421 & 1269 & 1064 & 987 & 857 & 895 \\
\hline Rhode Island & 1455 & 1405 & 1314 & 1139 & 989 & 910 & 887 \\
\hline \multirow[t]{2}{*}{ Connecticut } & 1512 & 1438 & 1280 & 1114 & 1040 & 915 & 930 \\
\hline & \multicolumn{7}{|c|}{ Middle Atlantic } \\
\hline New York & 1871 & 1895 & 1706 & 1466 & 1273 & 1070 & 1063 \\
\hline New Jersey & 1822 & 1736 & 1629 & 1457 & 1360 & 1208 & 1150 \\
\hline \multirow[t]{2}{*}{ Pennsylvania } & 1881 & 1841 & 1748 & 1536 & 1456 & 1322 & 1293 \\
\hline & \multicolumn{7}{|c|}{ South Atlantic } \\
\hline Delaware & 1509 & 1687 & 1596 & 1393 & 1332 & 1314 & 1269 \\
\hline Maryland & 1585 & 1598 & 1509 & 1302 & 1284 & 1237 & 1207 \\
\hline Virginia & 1954 & 1777 & 1710 & 1587 & 1544 & 1421 & 1408 \\
\hline North Carolina & 1920 & 1857 & 1822 & 1645 & 1606 & 1389 & 1351 \\
\hline South Carolina & 2030 & 1951 & 1851 & 1681 & 1635 & 1357 & 1324 \\
\hline Georgia & 2116 & 2103 & 2002 & 1962 & 1966 & 1672 & 1508 \\
\hline \multirow[t]{2}{*}{ Florida } & & & & 1899 & 1705 & 1726 & 1568 \\
\hline & \multicolumn{7}{|c|}{ East North Central } \\
\hline Ohio & 2550 & 2303 & 2131 & 1871 & 1696 & 1466 & 1360 \\
\hline Indiana & 2014 & 2307 & 2235 & 2139 & 1835 & 1702 & 1531 \\
\hline Illinois & & 2201 & 2235 & 2175 & 1869 & 1607 & 1471 \\
\hline Michigan & & 2121 & 1826 & 1834 & 1602 & 1463 & 1301 \\
\hline \multirow[t]{2}{*}{ Wisconsin } & & & & & 1569 & 1493 & 1594 \\
\hline & \multicolumn{7}{|c|}{ East South Central } \\
\hline Kentucky & 2371 & 2271 & 2070 & 1891 & 1890 & 1597 & 1517 \\
\hline Tennessee & 2424 & 2302 & 2204 & 2033 & 1916 & 1594 & 1483 \\
\hline Alabama & & & 2252 & 2198 & 2075 & 1637 & 1536 \\
\hline \multirow[t]{2}{*}{ Mississippi } & 2509 & 2089 & 2222 & 2113 & 2053 & 1776 & 1582 \\
\hline & \multicolumn{7}{|c|}{ West North Central } \\
\hline Minnesota & & & & & & 1508 & 1619 \\
\hline Iowa & & & & & 1837 & 1726 & 1636 \\
\hline Missouri & & 2375 & 2189 & 2223 & 1960 & 1581 & 1532 \\
\hline Dakota & & & & & & & 1157 \\
\hline Nebraska & & & & & & & 1460 \\
\hline \multirow[t]{2}{*}{ Kansas } & & & & & & & 1496 \\
\hline & \multicolumn{7}{|c|}{ West South Central } \\
\hline Arkansas & & & 2159 & 2205 & 2160 & 1843 & 1727 \\
\hline Louisiana & & 1904 & 1845 & 1738 & 1597 & 1294 & 1320 \\
\hline \multirow[t]{2}{*}{ Texas } & & & & & & 1745 & 1761 \\
\hline & \multicolumn{7}{|c|}{ Mountain } \\
\hline Colorado & & & & & & & 764 \\
\hline New Mexico & & & & & & 1265 & 1406 \\
\hline Utah & & & & & & 1513 & 2004 \\
\hline \multirow[t]{2}{*}{ Nevada } & & & & & & & 1270 \\
\hline & \multicolumn{7}{|c|}{ Pacific } \\
\hline Washington & & & & & & & 1847 \\
\hline Oregon & & & & & & 2005 & 2104 \\
\hline California & & & & & & 1111 & 1287 \\
\hline
\end{tabular}

The source of data is Yasuba (1962, Table II-7).

ductivity and/or transportation costs in various sectors. These technological factors are alternatives to the hypothesis that international immigration alone was the cause of the demographic changes. Let us review, below, the arguments suggesting that all these variables are sound driving forces. 
To discuss the possible effects of international immigration, it is interesting to start by observing that the vast majority of investment in productive land, after 1800, was done in the West. In other words, one can view the Eastern seaboard of the US has having a fixed stock of productive land as off 1800 , while in the West households could accumulate productive land. In an economy mostly dominated by agriculture, a fixed stock of land means decreasing returns to scale. Thus, as total population grew, the West was the region where growth could be higher than in the East. In short, population growth may have "pushed" Americans out of the East toward the West. The question is: which part of population growth was the most important for this mechanism? The part driven by natural increase or the part driven by international immigration?

How could technological progress have affected the US demography? First, and as mentioned earlier, there was productivity gains in land-improvement activities. These gains made the cost of settling into the West lower and contributed to the westward migration. Second, technological progress also improved transportation for goods and people. This, again, contributed positively to the westward migration. Third, technological progress also permitted real wage growth in the East despite decreasing returns to scale. This effect weakened the incentive to move westward. Finally, real wage growth affected the rate of natural increase through childbearing decisions. This point is discussed in more details below.

Birth ratios were higher in the West than in the East but they declined in both regions. By 1900, they had converged to a common value. ${ }^{4}$ Various mechanisms could be responsible for the declining birth ratios. Greenwood et al. (2005), for example, suggest that raising children is a time-consuming activity so that, as the wage rate grows, the optimal number of children declines. This framework, however, predicts low fertility in high-wage regions, a contradiction to historical facts since the real wage rate was higher in the West than in the East. ${ }^{5}$ One can imagine, however, that land availability in the West promoted higher fertility despite the opportunity cost of raising children. Yasuba (1962) suggests that in a rural economy, young individuals can establish themselves as households more easily if land is cheap. This promotes early marriage, and higher marital fertility than in areas where land is relatively less abundant. Another effect might come from the fact that a large family is a more valuable asset in rural areas than in urban areas: child labor can more easily be used on the family farm. Easterlin (1976) proposes a "bequest model" to rationalize this. His model prescribes that parents feel concerned with the welfare of their offspring and decide how much to give them for their start in life. In a land-abundant region it is cheaper to give one's child a start in life than in a region where land is less abundant. The first reason is that land is cheaper so endowing a child with a parcel of land is more affordable than elsewhere. Second, bequests do not have to be parcels of land. Parents may wish to endow their kids with any form of non-physical capital. This was more easily achieved in a high-real-wage area like the West.

The link between fertility and land availability is quite solid. Yasuba (1962) reports rank correlations between the birth ratio and a measure of land availability: the number of persons per 1000 acres of arable land. As he points out, one could argue that this measure also captures the urbanization movement that took place during the nineteenth century. ${ }^{6}$ To address this issue, he also computes the rank correlation between the birth ratio and the proportion of urban population by states. Table 3 reports his results. From these numbers, he concludes that the relationship between fertility and density is "more than an indirect analysis of the relationship between urbanization and fertility."

Table 3

Rank correlations with the birth ratio, US, 1800-1860

\begin{tabular}{|c|c|c|c|c|c|c|c|}
\hline & 1800 & 1810 & 1820 & 1830 & 1840 & 1850 & 1860 \\
\hline pop./acres of land & -0.633 & -0.848 & -0.802 & -0.773 & -0.675 & -0.604 & -0.526 \\
\hline prop. of urban pop. & -0.468 & -0.360 & -0.544 & -0.409 & -0.495 & -0.593 & -0.366 \\
\hline
\end{tabular}

The source of data is Yasuba (1962, Tables V.4 and V.10). The figures correspond to the rank correlation between the birth ratio and the population per acres of land (or the proportion of urban population) across states.

\footnotetext{
4 See Easterlin (1976).

5 See Coelho and Shepherd (1976) and Margo (2000).

6 See Greenwood and Seshadri (2002) for an analysis of the relationship between urbanization and fertility.
} 


\section{The model}

The economy has three noticeable features: fertility, migration and investment in land. A household lives for three periods: one as a child and two as an adult. Only young adults work. There are two locations called East and West, and a single consumption good is produced in each location with the services of labor, improved land and an intermediate good. The latter is produced in the East only, and there is a transportation cost associated with its use in the West. Another transportation cost is associated with labor moving from one location to the other.

The amount of land services in the East is fixed. In the West, there is a land-improvement sector that buys raw land from a government. It also hires western labor to operate its technology and sells newly improved land to the households who, in turn, rent it to the consumption-good sectors.

Preferences are defined over consumption and the number of children. Households can choose where to live, and they make this choice only once in their life, at the beginning of adulthood, before deciding how many children to have. The childbearing period is the first period of adulthood.

\subsection{Firms}

\subsubsection{Intermediate good}

The technology is $x_{t}=z_{x t} h_{x t}^{e}$ where $x_{t}$ is the total output of the sector, $z_{x t}$ is an exogenous productivity parameter and $h_{x t}^{e}$ is eastern labor. Let $q_{x t}$ denote the price of $x$ in the East. In the West, the price of the good is $q_{x t}\left(1+\tau_{x t}\right)$, where $\tau_{x t}$ is an iceberg cost representing the state of the transportation technology. The optimization problem of the firm is:

$$
\max _{h_{x t}^{e}}\left\{q_{x t} x_{t}-w_{t}^{e} h_{x t}^{e}\right\}
$$

where $w_{t}^{e}$ denotes the eastern real wage rate.

\subsubsection{Consumption good}

The technology in this sector is described by

$$
y_{t}^{j}=z_{y t}\left(h_{y t}^{j}\right)^{\mu}\left(x_{t}^{j}\right)^{\phi}\left(l_{t}^{j}\right)^{1-\phi-\mu}, \quad \mu, \phi \in(0,1),
$$

where the superscript $j$ refers to the location. The variables $h_{y t}^{j}, x_{t}^{j}$ and $l_{t}^{j}$, are inputs of labor, intermediate good and improved land, respectively. The objective of the eastern and western sectors are

$$
\max _{h_{y t}^{e}, x_{t}^{e}, l_{t}^{e}}\left\{y_{t}^{e}-w_{t}^{e} h_{y t}^{e}-q_{x t} x_{t}^{e}-r_{t}^{e} l_{t}^{e}\right\}
$$

and

$$
\max _{h_{y t}^{w}, x_{t}^{w}, l_{t}^{w}}\left\{y_{t}^{w}-w_{t}^{w} h_{y t}^{w}-q_{x t}\left(1+\tau_{x t}\right) x_{t}^{w}-r_{t}^{w} l_{t}^{w}\right\},
$$

where $r_{t}^{j}$ denotes the rental price of improved land in location $j$.

\subsubsection{Land-improvement}

Eastern land is fixed: $l_{t}^{e}=l^{e}$. In the West, the variable $l_{t}^{w}$, which represents the productive services of improved land, can increase. Specifically, the total stock of western land is fixed and represented by the unit interval, but the fraction of it which is improved and productive is a choice variable. The services of productive land, measured in efficiency units, are given by $l_{t}^{w}=\int_{0}^{l_{t}} \Lambda(u) \mathrm{d} u$ where $l_{t}$ is the stock of improved land measured in physical units, and $\Lambda$ is the density of efficiency units of land. The density function is $\Lambda(u)=1-u^{\theta}$ where $\theta>0$.

The technology for accumulating new productive land requires the use of labor only. Thus, the law of motion for the stock of improved land is

$$
l_{t+1}=l_{t}+z_{l t} h_{l t}^{w}
$$

where $z_{l t}$ is a technology parameter and $h_{l t}^{w}$ is western labor employed in the sector. Observe that the stock of improved land does not depreciate. 
The profit of period $t$, during which the land-improvement sector improves the land in the interval $\left[l_{t}, l_{t+1}\right]$, is given by

$$
\pi_{t}\left(l_{t}, l_{t+1}\right)=q_{t}^{w} \int_{l_{t}}^{l_{t+1}} \Lambda(u) \mathrm{d} u-\frac{w_{t}^{w}}{z_{l t}}\left(l_{t+1}-l_{t}\right)-\int_{l_{t}}^{l_{t+1}} q_{t}^{r}(u) \mathrm{d} u .
$$

The variable $q_{t}^{w}$ is the price of productive land services, and the function $q_{t}^{r}(u)$ is the price of raw land set by the government, the discussion of which is postponed to Section 2.4. The optimization problem of the firm is

$$
\begin{aligned}
& \max _{\left\{h_{l t}^{w}\right\}_{t \geqslant 1}} \pi_{1}\left(l_{1}, l_{2}\right)+\sum_{t=2}^{\infty}\left(\prod_{\tau=2}^{t} i_{\tau}\right)^{-1} \pi_{t}\left(l_{t}, l_{t+1}\right) \\
& \text { subject to } l_{t+1}=l_{t}+z_{l t} h_{l t}^{w}, \quad t \geqslant 1, l_{1} \text { given, }
\end{aligned}
$$

where $i_{t}$ is the gross interest rate. Along an optimal trajectory, the marginal profit of improving the land up to point $l_{t+1}$ during period $t$ must be the same as the marginal profit from postponing this decision for one period:

$$
q_{t}^{w} \Lambda\left(l_{t+1}\right)-\frac{w_{t}^{w}}{z_{l t}}-q_{t}^{r}\left(l_{t+1}\right)=\frac{1}{i_{t+1}}\left(q_{t+1}^{w} \Lambda\left(l_{t+1}\right)-\frac{w_{t+1}^{w}}{z_{l, t+1}}-q_{t+1}^{r}\left(l_{t+1}\right)\right) .
$$

\subsection{Households}

\subsubsection{Decision problem}

Denote the lifetime utility for an age- 1 household by $U\left(c_{1}, c_{2}, n_{1}\right)$. The variables $c_{1}$ and $c_{2}$ represent consumption and $n_{1}$ is the number of children. Denote the cost of raising $n$ children, measured in consumption units, by $C(n)$. There are three types of age- 1 households: those who never change location, call them Easterners and Westerners, and those who move, call them Movers. Let the superscript $j=e, w, m$ denotes the type of a household. ${ }^{7}$ A household of type $j=e, w$ solves the following maximization problem:

$$
V_{t}^{j}=\max _{c_{1 t}^{j}, c_{2, t+1}^{j}, n_{1 t}^{j}}\left\{U\left(c_{1 t}^{j}, c_{2, t+1}^{j}, n_{1 t}^{j}\right): c_{1 t}^{j}+\frac{c_{2, t+1}^{j}}{i_{t+1}}+C\left(n_{1 t}^{j}\right)=w_{t}^{j}+T_{t}\right\}
$$

where $T_{t}$ is a transfer received from the government. The program of a Mover going from East to West is

$$
V_{t}^{m}=\max _{c_{1 t}^{m}, c_{2, t+1}^{m}, n_{1 t}^{m}}\left\{U\left(c_{1 t}^{m}, c_{2, t+1}^{m}, n_{1 t}^{m}\right): c_{1 t}^{m}+\frac{c_{2, t+1}^{m}}{i_{t+1}}+C\left(n_{1 t}^{m}\right)+\tau_{h t}=w_{t}^{w}+T_{t}\right\}
$$

where $\tau_{h t}$ is the moving cost. Observe that a Mover going to the West receives the western wage rate since moving takes place at the beginning of adulthood, before any other decisions. In equilibrium, a household in the East must be indifferent between staying and moving to the West: $V_{t}^{e}=V_{t}^{m}$. The presence of the moving cost implies, therefore, that the wage rate is higher in the West than in the East. Hence, only westward migration takes place. For this reason, the superscript $m$ always refers to a mover going from the East toward the West.

\subsubsection{Preferences and the cost of raising children}

The optimality condition for fertility is

$$
U_{3}\left(c_{1}, c_{2}, n_{1}\right)=U_{1}\left(c_{1}, c_{2}, n_{1}\right) C^{\prime}\left(n_{1}\right),
$$

where time subscripts and type superscripts are dropped to simplify notations. In words, at an optimum, the marginal benefit of a child, measured by the left-hand side, must equal its marginal cost. The latter appears in the right-hand side and is the product of the marginal utility of consumption and the marginal consumption cost of a child. The choice of the functional forms for $U$ and $C$ is dictated by two facts that the model aims at matching: the decline of fertility through time, and the excess fertility in the West, that is in low-density regions.

$\overline{7}$ Notice a slight abuse of notations here, since $j$ referred to the location in the description of firms, while it refers to the type of a household here. 
As mentioned earlier, the decline in fertility can be accounted for along the lines of Greenwood et al. (2005). Their approach suggests the following choices for preferences and the cost of raising children:

$$
U\left(c_{1}, c_{2}, n_{1}\right)=\ln \left(c_{1}+\bar{c}\right)+\beta \ln \left(c_{2}+\bar{c}\right)+\sigma \ln \left(n_{1}\right)
$$

and

$$
C(n)=w \frac{n_{1}}{z_{k}},
$$

where $\sigma>0$ and $\beta \in(0,1)$. In this formulation, the parameter $\bar{c}$ is a positive constant affecting the marginal utility of consumption. Its purpose is to allow the analysis to benefit from the simplicity of the logarithmic utility, while offering flexibility in the choice of the curvature of the utility function. As will become transparent soon, this device is useful to generate the decline in fertility. The parameter $z_{k}$ is a positive constant which measures the "productivity" of non-market time in the child-raising activity. The quantity $n_{1} / z_{k}$, therefore, is the time spent raising $n_{1}$ children. The consumption cost of $n_{1}$ children is the market value of this time. With these functional forms, the optimality condition for fertility writes

$$
\frac{\sigma}{n_{1}}=\frac{w / z_{k}}{c_{1}+\bar{c}}
$$

Observe that, along an equilibrium path where consumption and wages grow at the same rate the marginal cost of a child increases and, therefore, fertility must decrease. Notice also that, when $\bar{c}=0$, fertility is constant along a balanced growth path. Asymptotically, the effect of $\bar{c}$ vanishes and fertility converges to this constant.

The framework above implies that fertility is lower in the West, where wages are higher. To solve this problem, the discussion in Section 1.2 suggested that the density of population could enter the first order condition for fertility. There are two approaches here. The first relies on a modification of preferences, the second on a modification of the child-raising technology. As will become clear shortly, the two approaches share some similarities-a standard feature of household production models, pointed out by Benhabib et al. (1991).

The first approach consists in introducing density into the utility function. More precisely, let preferences be represented by

$$
U\left(c_{1}, c_{2}, n_{1}\right)=\ln \left(c_{1}+\bar{c}\right)+\beta \ln \left(c_{2}+\bar{c}\right)+\sigma\left(1+\frac{\kappa}{d}\right) \ln \left(n_{1}\right)
$$

where $\kappa>0$ and $d$ is the density of population in the region where the household is living. In a densely populated area, the marginal utility of a child is lower: a "crowding" effect. One can imagine, for example, that parents internalize the fact that a child born in a crowded area may have a harder time finding land and setting up his own farm. They derive less utility from the child because they foresee that. The utility function in (10) proposes a shortcut to model this idea. The optimality condition for fertility, derived from combining (9) with (10), is

$$
\left(1+\frac{\kappa}{d}\right) \frac{\sigma}{n_{1}}=\frac{w / z_{k}}{c_{1}+\bar{c}}
$$

With this framework, a higher wage rate does not necessarily imply lower fertility if the density is small enough. As population grows, all the land gets eventually improved and the density of population increases in each region. This implies that in the long run the term $\kappa / d$ converges to zero. Then, fertility choices converge if wages are converging too.

Another approach to introducing density into the optimal fertility decision does not rely on preferences. It consists in introducing the density into the cost of raising kids. One can imagine that, in low-density regions, it is easier to have children working on a small area of land and contributing to the household's income. Thus, although it still takes time to raise a child, this time cost is partly offset by "child labor." Suppose, for example, that the time needed to raise one child is given by $(1+\kappa / d)^{-1} / z_{k}$, which implies that the time cost of a child is increasing with density. The consumption cost for $n_{1}$ children becomes

$$
C\left(n_{1}\right)=w \frac{n_{1}}{z_{k}}\left(1+\frac{\kappa}{d}\right)^{-1}
$$

With this formulation, a high-wage low-density area can potentially have high fertility. When the land gets more settled, it becomes harder to find such areas of land for children to work (e.g., the yard on the farm becomes smaller), 
and the effect of density on the cost of raising children vanishes. The optimality condition for fertility, derived from combining (12) with (8), is again given by Eq. (11). In what follows, the cost function (9) and the utility function (10) are used. ${ }^{8}$

\subsection{Demography}

Let $p_{t}^{w}$ and $p_{t}^{e}$ denote the number of age-1 Westerners and Easterners, respectively. Let $p_{t}^{m}$ denote the number of age-1 Movers going from East to West at date $t$. Movers are born in the East but leave it for the West. Their children are born in the West. Thus, the total age- 1 western population is $p_{t}^{w}+p_{t}^{m}$, while the total age- 1 eastern population is $p_{t}^{e}$. Let $f$ denote the rate of international immigration, and assume that immigrants arrive during the first period of their life, and become age- 1 adults during the next period. The law of motion for $p_{t}^{w}$ is

$$
p_{t+1}^{w}=p_{t}^{w} n_{1 t}^{w}+p_{t}^{m} n_{1 t}^{m}+f\left(p_{t}^{w}+p_{t}^{m}\right) .
$$

This equation dictates that the number of age- 1 Westerners at date $t+1$ has three sources. First they can be born from the current generation of Westerners: $p_{t}^{w} n_{1 t}^{w}$. Second, they can be born from the current generation of Movers: $p_{t}^{m} n_{1 t}^{m}$. Finally, they can also be moving into the West, directly from the rest of the world, in proportion $f$ of the current western population. The law of motion for $p_{t}^{e}$ is

$$
p_{t+1}^{e}=p_{t}^{e} n_{1 t}^{e}-p_{t+1}^{m}+f p_{t}^{e},
$$

that is, age-1 Easterners at $t+1$ are either born from the current generation or coming from the rest of the world. The term $-p_{t+1}^{m}$ indicates that one has to subtract those who decide to move out of the East at date $t+1$, since they are not Easterners by definition. The total age-1 population evolves in line with

$$
p_{t+1}^{w}+p_{t+1}^{e}+p_{t+1}^{m}=p_{t}^{w}\left(n_{1 t}^{w}+f\right)+p_{t}^{m}\left(n_{1 t}^{m}+f\right)+p_{t}^{e}\left(n_{1 t}^{e}+f\right) .
$$

The density of age-1 population in the East is $d_{t}^{e}=p_{t}^{e} / l^{e}$ and for the West it is given by $d_{t}^{w}=\left(p_{t}^{w}+p_{t}^{m}\right) / l_{t}^{w}$.

\subsection{Land policy}

During the nineteenth century the land policy changed a number of times, and was the subject of intense political debates. ${ }^{9}$ The general rule was that western raw land was sold to settlers, by the US government, through an auction process. The difficulties found in enforcing property rights on the frontier, however, forced the US government to recognize squatters and legalize their occupancy of the land at a number of occasions throughout the century. In 1862, the Homestead Act was passed which, essentially, consisted in giving the land out for free. Formally, the Homestead Act writes $q_{t}^{r}(u)=0$ for all $t$ and $u$. The consequence of this subsidy (giving out free land) is that the government has no resources to transfer to households, hence $T_{t}=0$. Later, the quantitative analysis section considers an alternative land policy.

\subsection{Equilibrium}

\subsubsection{Definition of equilibrium}

In equilibrium bonds and land must deliver the same rate of return, hence

$$
i_{t+1}=\frac{r_{t+1}^{j}+q_{t+1}^{j}}{q_{t}^{j}}, \quad j=e, w .
$$

The western and eastern labor markets must clear:

\footnotetext{
8 Notice that, although the two approaches deliver the same first order condition for fertility, they are not equivalent since they involve different value functions and, therefore, different allocations. As will appear in Section 3.1, however, the methodology used in the empirical exercise implies that the quantitative difference between the allocations obtained with each method is small.

9 See Atack et al. (2000).
} 


$$
\begin{aligned}
& p_{t}^{w}\left(1-n_{1 t}^{w} / z_{k}\right)+p_{t}^{m}\left(1-n_{1 t}^{m} / z_{k}\right)=h_{y t}^{w}+h_{l t}^{w}, \\
& p_{t}^{e}\left(1-n_{1 t}^{e} / z_{k}\right)=h_{y t}^{e}+h_{x t}^{e} .
\end{aligned}
$$

In Eqs. (16) and (17) the left-hand side are western and eastern labor supplies, taking into account the time spent raising children for each type of household. The right-hand side are labor demands from the sectors operating in each region. The market for the intermediate good must clear too:

$$
x_{t}^{w}+x_{t}^{e}=x_{t} .
$$

Finally, the market clearing condition for savings is

$$
p_{t}^{w} s_{t+1}^{w}+p_{t}^{m} s_{t+1}^{m}+p_{t}^{e} s_{t+1}^{e}=q_{t}^{w} l_{t+1}^{w}+q_{t}^{e} l^{e}
$$

where $s_{t+1}^{j}$ are the savings of an age-1 household of type $j$ during period $t$, which will pay off during period $t+1$.

Definition 1. A competitive equilibrium is composed of: (i) allocations for households $\left\{c_{a t}^{j}, n_{1 t}^{j}\right\}$ for $j=e, w, m$ and $a=1,2$ and firms $\left\{h_{y t}^{w}, h_{l t}^{w}, h_{y t}^{e}, h_{x t}^{e}, l^{e}, l_{t}^{w}\right\}$; (ii) prices $\left\{w_{t}^{j}, r_{t}^{j}, q_{t}^{j}, q_{x t}, i_{t}\right\}$ for $j=e, w$, such that

(1) The sequence $\left\{h_{x t}^{e}\right\}$ solves (1) at all $t$ given prices;

(2) The sequence $\left\{h_{y t}^{e}, x_{t}^{e}, l^{e}\right\}$ solves (2) at all $t$ given prices;

(3) The sequence $\left\{h_{y t}^{w}, x_{t}^{w}, l_{t}^{w}\right\}$ solves (3) at all $t$ given prices;

(4) The sequence $\left\{h_{l t}^{w}\right\}$ solves (4) given prices;

(5) The sequences $\left\{c_{a t}^{j}, n_{1 t}^{j}\right\}$ for $j=e, w$ solve (6) given prices; the sequence $\left\{c_{a t}^{m}, n_{1 t}^{m}\right\}$ solves (7); and households choose their location optimally, that is $V_{t}^{e}=V_{t}^{m}$;

(6) Population growth is described by (13) and (14);

(7) Market clears, or conditions (15)-(19) hold.

\subsubsection{Balanced growth}

In the long run all the land is improved in the West: $l_{t}^{w} \rightarrow \int_{0}^{1} \Lambda(u) \mathrm{d} u \equiv l^{w}$, as $t \rightarrow \infty$. Hence, employment in the land-improvement sector converges to zero: $h_{l t}^{w} \rightarrow 0$. Assume that transportation costs converge to zero too: $\tau_{h t}, \tau_{x t} \rightarrow 0$ as $t \rightarrow \infty$, implying that eastern and western wages converge. Let total factor productivity grow by a factor $g_{z}>1$ per period, in the consumption and intermediate good sectors, and assume that $g_{z}$ is large enough to warrant wage growth. In such case, fertility is the same for all types and is constant through time. ${ }^{10}$ Denote it by $n_{1}$ so that, in each location, the rate of population growth is $n_{1}+f$. Then, output in the intermediate good sector grows at rate $g_{z}\left(n_{1}+f\right)$ and the growth rate of the economy becomes

$$
g=g_{z}^{1+\phi}\left(n_{1}+f\right)^{\phi+\mu} .
$$

Real wages are growing at rate $g /\left(n_{1}+f\right)$. The optimality conditions for households imply that individual consumption and savings grow at the same rate as real wages. Thus aggregate consumption grows at rate $g$. Since the stock of

$\overline{10}$ The first order conditions for problem (6) when the cost function (9) and the utility function (10) are used are

$$
\frac{c_{1 t}^{j}+\bar{c}}{w_{t}^{j}}=\frac{1}{1+\beta}\left(1-\frac{n_{1 t}^{j}}{z_{k}}+\frac{\bar{c}}{w_{t}^{j}}\left(1+\frac{1}{i_{t+1}}\right)\right)
$$

and

$$
\frac{c_{1 t}^{j}+\bar{c}}{w_{t}^{j}}=\frac{n_{1 t}^{j} / z_{k}}{\sigma}\left(1+\frac{\kappa}{d_{t}^{j}}\right)^{-1} .
$$

In the long run the terms $\bar{c} / w_{t}^{j}$ and $\kappa / d_{t}^{j}$ converge to zero so that

$$
\frac{n_{1 t}^{j}}{z_{k}}\left(\frac{1}{\sigma}+\frac{1}{1+\beta}\right)=\frac{1}{1+\beta} .
$$

Hence, in the long run, fertility is constant and identical for Easterners, Westerners and Movers. 
land is fixed, the price of land must grow at rate $g$ too. The firms optimality conditions imply also that the rental rate for land increases at rate $g$, hence Eq. (15) implies a constant interest rate.

\section{Quantitative analysis}

This section presents the quantitative analysis of the model in two parts. The first consists in assigning numerical values to the model's parameters. For some, but not all, one can use a priori information. The remaining parameters are estimated using US data.

The second part of the section presents a set of counterfactual experiments. The first one addresses the following question: How did international immigration affect the US demography? One motivation for asking this question is the calculation mentioned in the Introduction. If one computed total population growth between 1800 and 1900, using the observed rate of natural increase as the growth rate, one would find that in 1900 the US population would have been $52 \%$ below its actual level. This would be a sizeable difference, and one could reasonably expect that it would have affected the economy and the demography as well. In particular, there would have been less demand on Eastern resources, and the Westward movement would have been less pronounced. This calculation suffers from a potential drawback, however, since it assumes that the rate of natural increase was unaffected by the absence of immigrants. But, precisely because one should expect economic variables to react to the absence of immigrants, one should also expect the rate of natural increase to react. A model of natural increase, such as the one developed earlier, allows one to avoid this drawback. The second set of experiments consists in assessing the effects of alternative driving forces built into the model. Specifically, these experiments ask how important was technological progress in production and transportation for the US demography during the nineteenth century? Finally, the last experiment proposes an alternative to the land policy described in Section 2.4.

\subsection{Calibration}

A period is 10 years. The rate of growth of $z_{y t}$ and $z_{x t}$-the productivity variables in the consumption and intermediate good sectors-are identical and, following Gallman (2000, Table 1.4), set to 0.55\% per year from 1800 to 1840 and $0.71 \%$ per year from 1840 to 1900 . The rate of growth of $z_{l t}$, the productivity in the land-improvement sector is set to $0.3 \%$ per year from 1800 to 1860 and $0.6 \%$ per year from 1860 to 1900 . The former figure is the rate of growth of labor productivity in agriculture. This does not correspond, strictly speaking, to land-improvement activities, but it is used to compensate the lack of data for this period. The latter number is derived from the rate of growth of labor productivity in land-clearing and breaking, fencing, draining and irrigating, following the work of Primack (1962). The initial values $z_{y, 1800}, z_{x, 1800}$ and $z_{l, 1800}$ are set to one.

O'Rourke and Williamson (1999) report a $1.5 \%$ annual rate of decline for transportation costs. This number is used for the two transportation costs in the model. The initial value for $\tau_{x}$ is $\tau_{x, 1800}=0.5 \times 0.86^{-5}$ which implies that, in 1850 , the value of $\tau_{x}$ is 0.5 , consistent with figures reported by Herrendorf et al. (2006). ${ }^{11}$ The choice of $\tau_{h, 1800}$ is discussed below.

Following Gallman (2000), the labor share is set to $\mu=0.6$ and the intermediate good share to $\phi=0.2$, the capital share. Given that the model's period is 10 years, the interpretation of the intermediate good as capital which fully depreciates is acceptable. As mentioned earlier, the rate of net migration is set to $f=5 \%$.

The remaining parameters are $a=\left(\beta, \theta, l^{e}, \tau_{h, 1800}, \sigma, \kappa, \bar{c}\right)$. They consist of the discount factor, the curvature parameter for the density of efficiency units of land, the stock of land services in the East, the initial cost of transportation, and utility parameters. To assign a value to $a$ proceed as follows. First, guess an initial value. Then, let the economy start off in 1800. Let the initial old population be 1, and assume that it is entirely located in the East. Fix the initial stock of improved land to $l_{1800}=0.06$, following Gallman (1986). ${ }^{12}$ From this point, compute the equilibrium trajectory of the economy, feeding in the paths of technology and transportation costs. The length of the equilibrium trajectory is 30 periods, although only the first ten periods, corresponding to the nineteenth century, are reported. Let

\footnotetext{
11 They report that the price difference for wheat, between the east and the Midwest, was $50 \%$ at mid-century.

12 Gallman (1986, Table B-5) reports the stock of improved land by regions. The stock is normalized by its value in 1900, implying that the initial value, $l_{1800}$, is $6 \%$.
} 
$p_{t}$ represent the total population at date $t$. Since households are alive for two periods and $p_{t}^{j}$ is the age-1 population of type $j$, the total population of type $j$ at date $t$ is $p_{t}^{j}+p_{t-1}^{j}$ and, therefore,

$$
p_{t}=\sum_{j=w, e, m} p_{t}^{j}+p_{t-1}^{j} .
$$

Define also

$$
\begin{aligned}
& \hat{P}_{t}(a)=\frac{p_{t}^{w}+p_{t-1}^{w}+p_{t}^{m}+p_{t-1}^{m}}{p_{t}}, \\
& \hat{Q}_{t}(a)=l_{t}, \\
& \hat{R}_{t}(a)=w_{t}^{w} / w_{t}^{e},
\end{aligned}
$$

where $\hat{P}_{t}(a)$ is the predicted ratio of western to total population at $a$. Let $P_{t}$ be its empirical counterpart as displayed in Fig. 2. The terms $\hat{Q}_{t}(a)$ and $\hat{R}_{t}(a)$ are the stock of improved land and the West-East wage ratio predicted by the model. Let $Q_{t}$ and $R_{t}$ be their empirical counterparts. ${ }^{13}$ Finally, define

$$
M(a)=\left(\begin{array}{c}
i_{1900}-1.07 \\
p_{1900} / p_{1800}-13.6 \\
f_{1800}^{w} / f_{1800}^{e}-1.3 \\
f_{1900}^{w} / f_{1900}^{e}-1.0 \\
f_{1900} / f_{1800}-0.5
\end{array}\right)
$$

where $f_{t}^{w}, f_{t}^{e}$ and $f_{t}$ are western, eastern and total fertility, respectively. ${ }^{14}$ Let $a$ solve

$$
\min _{a} \sum_{t \in \mathcal{T}}\left[\left(\hat{P}_{t}(a)-P_{t}\right)^{2}+\left(\hat{Q}_{t}(a)-Q_{t}\right)^{2}+\left(\hat{R}_{t}(a)-R_{t}\right)^{2}\right]+M(a)^{\top} M(a)
$$

where $\mathcal{T}=\{1800,1810, \ldots, 1900\} .{ }^{15}$ The first part of this objective function implies that the economy is matched to the time series of the ratio of Westerners, the wage ratio and the stock of improved land. The data on the stock of improved land and the ratio of Westerners are useful in pinning down the values of $\theta$ and $l^{e}$, the curvature of the density of land services and the stock of improved land in the East. The West-East wage ratio helps pinning down the initial value of the moving cost, $\tau_{h, 1800}$.

The second part of the objective function includes five additional restrictions. The first is the difference between the model's gross interest rate in 1900 and 1.07. Hence, this part of the objective function implies that, in the balanced growth path, the interest rate of the model economy is about $7 \%$. This restriction helps pinning down the discount factor, $\beta$. The remaining moments are related to population growth and fertility. First, there is a measure of total population growth from 1800 to 1900 . The US data shows that total population was multiplied by 13.6 during this period, and the parameters are restricted to imply such growth in the model. This restriction acts mostly on parameters such as $z_{k}$ and the utility parameters controlling the level of fertility. The third and fourth line of $M(a)$ impose a $30 \%$ difference between western and eastern fertility in 1800 , and convergence by 1900 . The $30 \%$ difference corresponds to the average difference between eastern and western birth ratios in 1800 in Table $2 .{ }^{16}$ These two restrictions act mostly on $\kappa$. The last line of $M(a)$ imposes a 50\% decline in fertility. This restriction affects mostly the value of $\bar{c}$.

Table 4 presents the baseline calibration and Fig. 4 the quality of the match between the model and the US data. As one can see the model fits the data reasonably well. In particular, it is able to generate a fertility difference in favor of the West while the wage rate is higher in the West than in the East. The model matches closely the growth of total population as well as its geographic distribution. Average fertility, however, does not decline as much as in the US data: $20 \%$ vis à vis $50 \%$. This discrepancy is mostly due to $\bar{c}$ which affects both the level of fertility and its reaction to

\footnotetext{
13 The source for the wage ratio is Coelho and Shepherd (1976) and Margo (2000). The source for the stock of improved land is Gallman (1986).

14 Specifically, western fertility is the weighted average of the fertility of Westerners and Movers, eastern fertility is simply $n_{1 t}^{e}$ and total fertility is the weighted average of the fertility of the three types of households.

15 This procedure implies that the choice of the modeling strategy for the household's problem, discussed in Section 2.2.2, matters little for the equilibrium allocation since the latter is imposed through the solution of the minimization problem above.

16 The central states (Ohio, Indiana, Kentucky, Tennessee and Mississippi) correspond to the West.
} 
Table 4

Baseline calibration

\begin{tabular}{|c|c|c|c|}
\hline \multirow[t]{7}{*}{$\begin{array}{l}\text { Preferences } \\
\text { Technology }\end{array}$} & \multicolumn{3}{|c|}{$\begin{array}{l}\beta=0.98, \bar{c}=0.09, \sigma=0.525, \kappa=15 \\
\mu=0.6, \phi=0.2, \theta=0.1, z_{k}=3.7, l^{e}=0.02\end{array}$} \\
\hline & \multicolumn{2}{|c|}{ Initial value } & \multirow{2}{*}{$\frac{\text { Annual growth rate }}{0.55 \%(1800-40) \text { and } 0.71 \%(1840-00)}$} \\
\hline & $z y$ & 1.0 & \\
\hline & $z_{x}$ & 1.0 & $0.55 \%(1800-40)$ and $0.71 \%(1840-00)$ \\
\hline & $z_{l}$ & 1.0 & $0.30 \%(1800-60)$ and $0.60 \%(1860-00)$ \\
\hline & $\tau_{x}$ & 1.06 & $-1.5 \%$ \\
\hline & $\tau_{h}$ & 0.07 & $-1.5 \%$ \\
\hline
\end{tabular}

the wage rate. One can see from Eq. (11) that larger values of $\bar{c}$ imply, at the same time, larger fertility rates everything else equal, and faster decline in fertility in response to an increase in the wage rate. The constraint that population must be multiplied by 13.6, imposed in the objective function, pushes the minimization routine toward "low" values of $\bar{c}$, reducing at the same time the magnitude of the decrease in fertility.

\subsection{Counterfactual experiments}

The first experiment asks the following question: How did international immigration affect the US economy during the nineteenth century? To answer this question, the model is simulated under the calibration of Table 4, but with the rate of international immigration, $f$, set to zero. Figure 5 presents the results of this experiment. Its main message is that international immigration did not affect the US beyond its direct effect on population growth. Specifically, the biggest departures from the baseline simulations are in panels B and D. Panel B represents the stock of improved land which increases less in the case where no immigrants came to the US than in the baseline case. Although the difference is noticeable, one can argue that it is small. Panel D represents total population. Notice that fertility (panel C) is hardly affected by immigrants. To understand, observe that two forces are at work here. On the one hand, the absence of immigrants permits higher wages in the counterfactual economy and, hence, fertility tends to be lower. To be precise, the real wage rates in the counterfactual economy are initially identical to the those of the baseline economy. As time unfolds, however, the difference in total population between the two economies increases, and the wage difference increases too. In 1900, the regional real wages in the counterfactual economy are $8 \%$ above their counterparts in the baseline simulation (panel E). On the other hand, less population growth implies smaller regional densities (panel F) and, hence, higher fertility rates. Under the baseline calibration, the effects of these two opposing forces offset each other.

Five experiments measure the effects of technological progress. In the first, the equilibrium path of the economy is computed without decline in the transportation cost $\tau_{h t}$. In other words, $\tau_{h t}$ stays constant at its initial level but all other technology variables evolve as described in Table 4. In the second experiment, only the transportation cost for goods, $\tau_{x t}$, differs from the baseline case, and stays constant at its initial level. Experiments three to five consist in shutting down technological progress in $z_{l t}, z_{y t}$ and $z_{x t}$. Thus they are measuring the effects of productivity in land improvement, the production of the consumption good and that of the intermediate good, respectively. Figure 6 shows the results. The transportation cost for households is the main contributor to the westward shift of the population-panel A. Without the reduction in this cost, only $35 \%$ of the population would have settled the West in 1900 , versus $56 \%$ in the baseline case. The reduction in the transportation cost for goods and technological progress in the consumption good sector also contributed noticeably to the change in the geographic distribution of population. To understand this, notice that reductions in the transportation cost for goods makes it easier for the western sector to use the intermediate goods, which raises the marginal product of western labor and attracts Movers to the west. Technological progress in the consumption-good sector affects the distribution of population through various channels. On the one hand there is no wage growth in its absence. This pushes households out of the East toward the West, where they can use more land to compensate this lack of productivity. On the other hand, households face increasing transportation costs which, with decreasing real wages cannot be paid easily. This effect tends to reduce the number of Movers. Finally, the absence of wage growth promotes higher fertility and population growth (panel C). The change in fertility is not even, however, and eastern fertility exceeds western fertility. This difference drives the ratio of western to total population down. In terms of land improvement, panel B shows no great differences among the various 


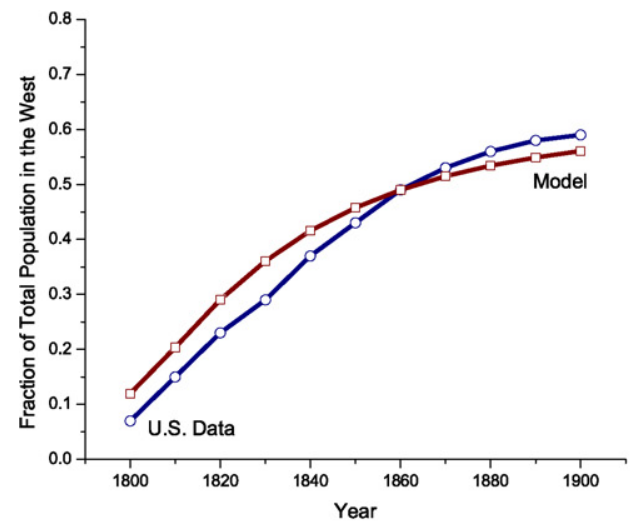

(A)

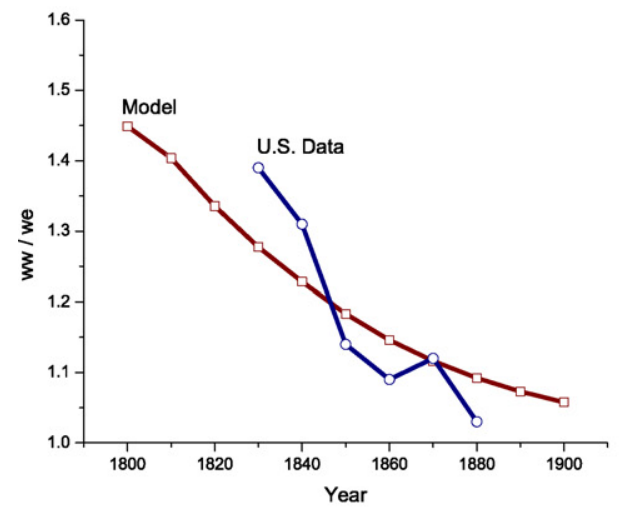

(C)

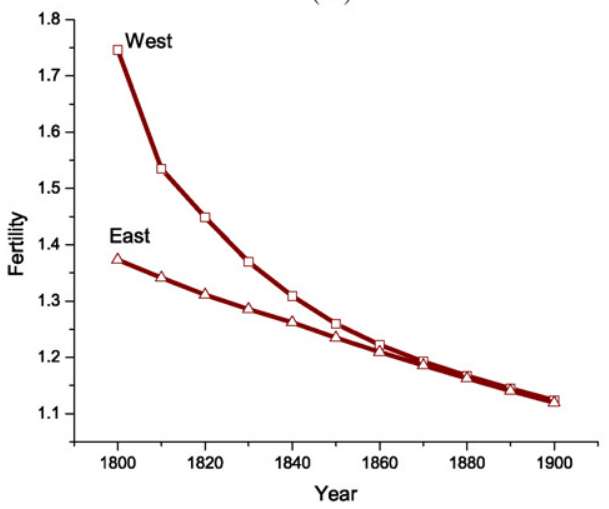

(E)

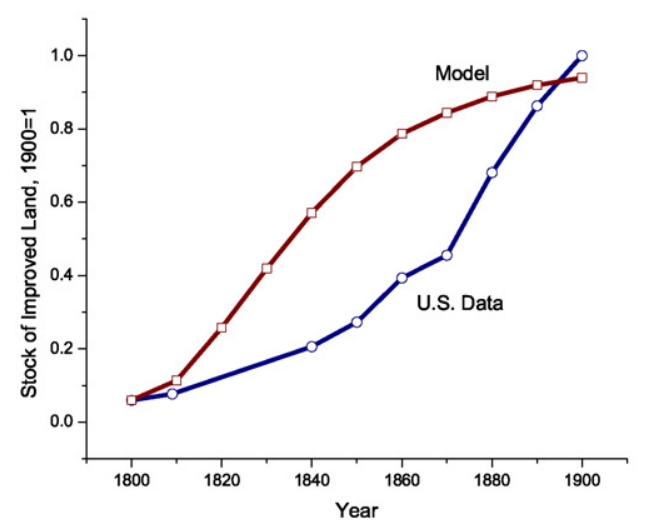

(B)

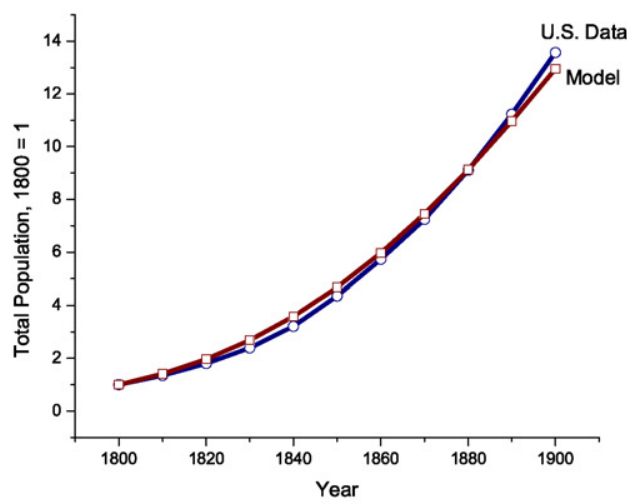

(D)

\begin{tabular}{lrr}
\hline \hline & Target & Model \\
\hline$i_{1900}$ & 1.07 & 1.06 \\
$p_{1900} / p_{1800}$ & 13.6 & 12.9 \\
$f_{1800}^{w} / f_{1800}^{e}$ & 1.3 & 1.27 \\
$f_{1900}^{w} / f_{1900}^{e}$ & 1.0 & 1.0 \\
$f_{1900} / f_{1800}$ & 0.5 & 0.8 \\
\hline
\end{tabular}

(F)

Panels A, B and C display the model's ability to fit the time series of the ratio of western to total population, the stock of improved land and the ratio of western to eastern real wages, respectively. Panel D displays the model's total population vis à vis its empirical counterpart. Panel E shows the western and eastern fertility rates predicted by the model. Finally, panel F indicates the model's ability to match the objectives in $M(a)$.

Fig. 4. The model's fit.

experiments. Yet, one can see that without technological progress in the consumption-good sector, the economy tends to accumulate more land while, without decreasing cost of transportation, it tends to accumulate less. ${ }^{17}$

17 The importance of the transportation revolution for the development of the American economy has been emphasized earlier. See, for example, Fishlow (1965). Likewise, the work of Primack (1962) documents the extent of technological progress in the land-improvement sector and its impact on western development. However, neither Fishlow nor Primack present these phenomena in the context of a calibrated version of the 


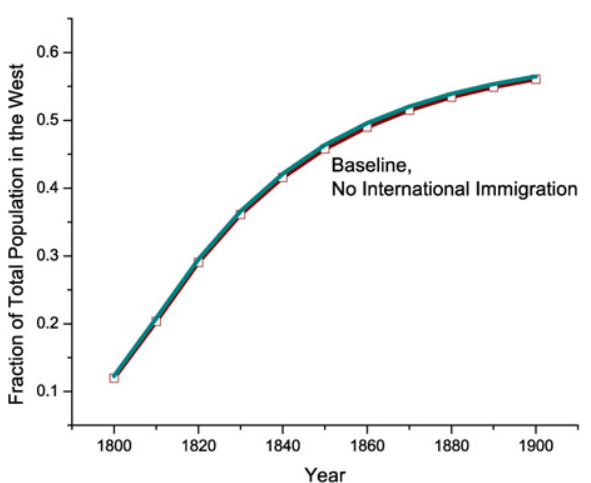

(A)

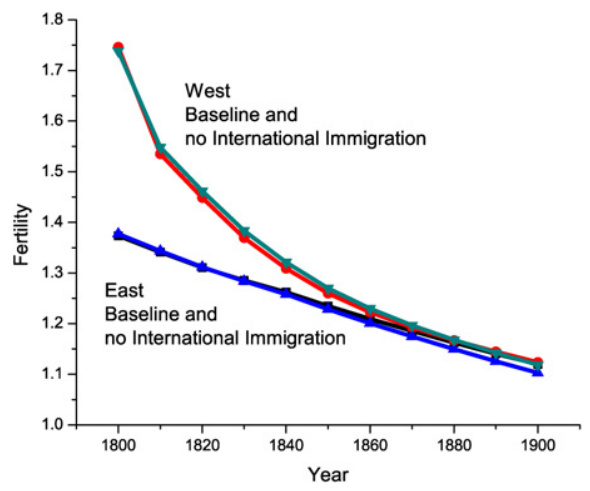

(C)

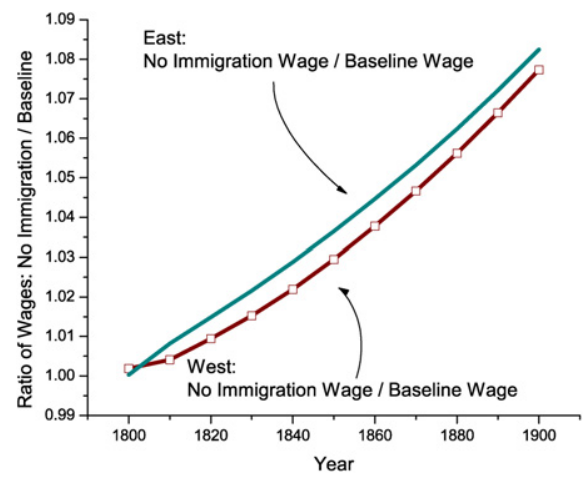

(E)

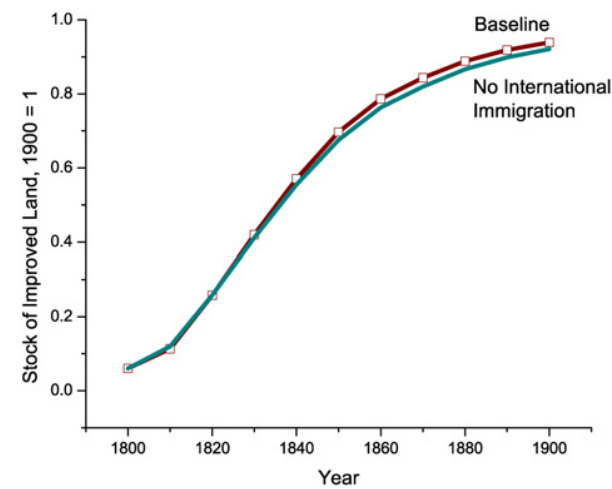

(B)

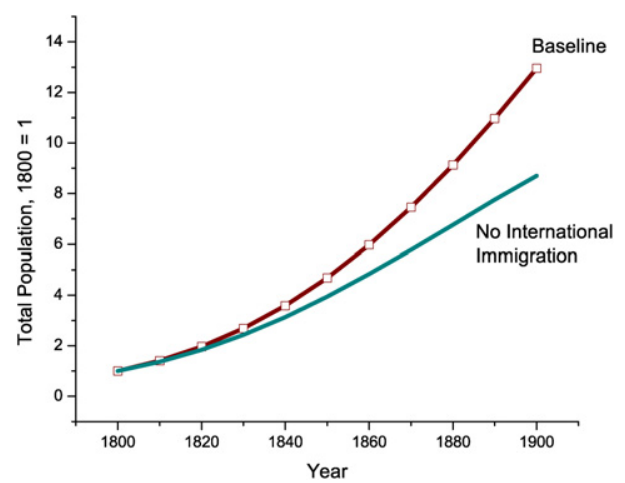

(D)

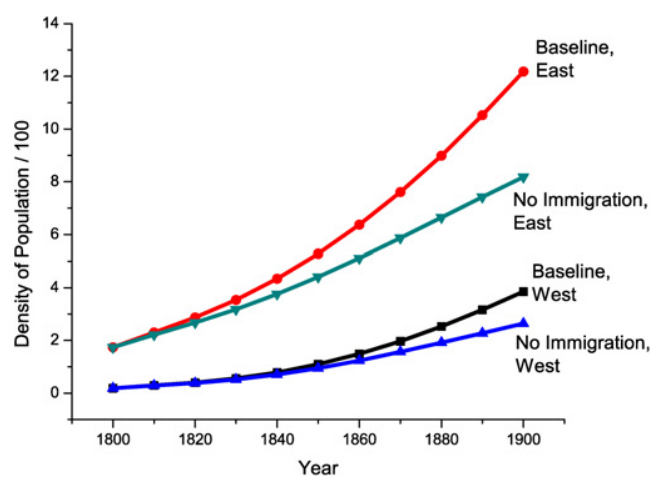

(F)

A: share of westerners in the total population in the baseline calibration and the counterfactual experiment; B: stock of improved land; C: regional fertility rates; D: total population; E: ratio of counterfactual wage rate to baseline wage rate in each region; F: density of population in each region.

Fig. 5. Counterfactual experiment-no international immigration.

The last experiment proposes an alternative land policy. What if the homestead act was never passed? Suppose that the US government sold raw land to the land-improvement sector, and contemplate the following price system. For $u \in\left[l_{t}, l_{t+1}\right]$ the government charges $q_{t}^{r}(u)=q_{t}^{w} \Lambda(u)-w_{t}^{w} / z_{l t}$ and for $u \geqslant l_{t+1}$, the government sets $q_{t}^{r}(u)=$ $q_{t+1}^{r}(u) / i_{t+1}$. Such a price function corresponds to what would have prevailed if land was traded on a competitive market. The price set for $u \in\left[l_{t}, l_{t+1}\right]$ corresponds to a zero-profit condition in the land improvement sector. The price set for $u \geqslant l_{t+1}$ corresponds to a no-arbitrage condition. One can also interpret the zero-profit condition as the 


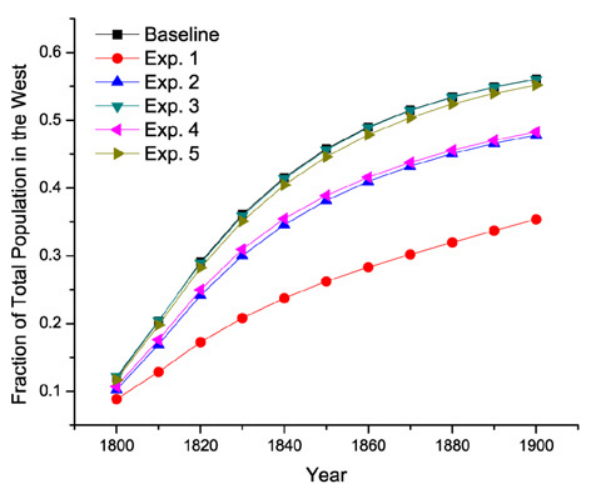

(A)

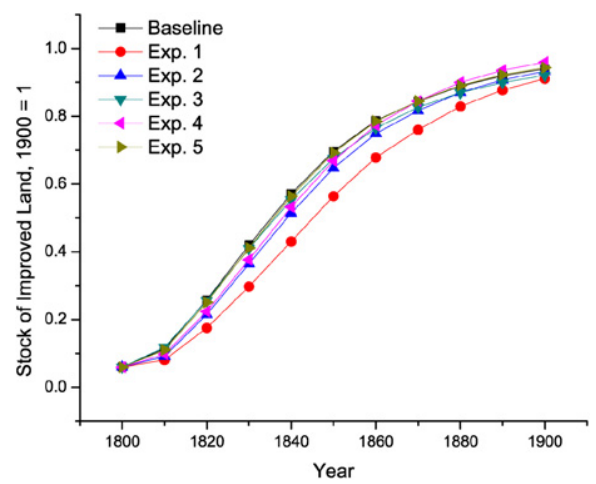

(B)

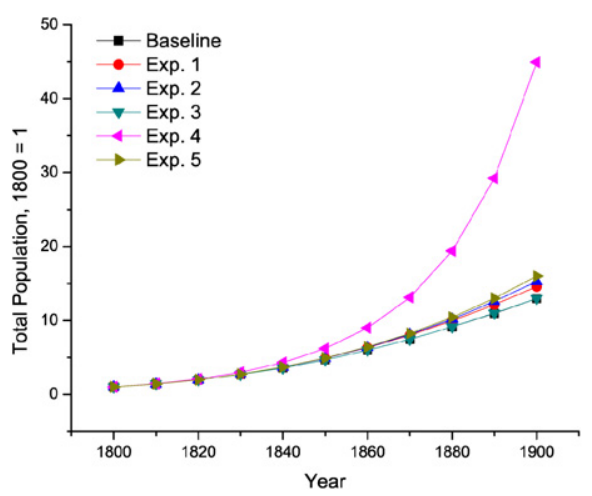

(C)

Experiment 1: no technological progress in the transportation of labor; Experiment 2: no technological progress in the transportation of goods; Experiment 3: no progress in land-improvement technology; Experiment 4: no progress in consumption-good technology; Experiment 5: no progress in intermediate good technology.

Fig. 6. C ounterfactual experiment—no technological progress.

outcome of an auction process: land-improvement firms bid for the land until there is no profit to extract. Under this policy, the government's transfer to a particular household is $T_{t}=\int_{l_{t}}^{l_{t+1}} q_{t}^{r}(u) \mathrm{d} u /\left(p_{t}^{w}+p_{t}^{e}+p_{t}^{m}\right)$. Figure 7 presents the result of this experiment. The main message, here, is that selling raw land instead of giving it out affects mostly the fertility rates (panel C), but is not enough to warrant significant changes in the stock of improved land (panel B) or the geographic distribution of population (panel A). To understand this result, contemplate first the optimality condition for the land-improvement sector, Eq. (5). Under the baseline calibration, the price of raw land, $q_{t}^{r}(u)$, is set to zero and, therefore, does not appear in the equation. Under the alternative policy, the price of raw land is not zero, but the no-arbitrage condition $q_{t}^{r}\left(l_{t+1}\right)=q_{t+1}^{r}\left(l_{t+1}\right) / i_{t+1}$, implies that it drops out of the equation. In other words, under the alternative policy the land-improvement firm cannot increase its value by reallocating purchases of raw land through time. Thus, in each case the pace of land accumulation depends on fundamentals only: technology and the quality of the land. The value of the land-improvement firm is different in the two economies, though. This difference is channeled, through transfers, to households and promotes an increase in fertility (panel C) hence faster population growth (panel D). The latter fuels an additional demand for improved land (the opposite of the no-immigration case) but, quantitatively, this effect is small. ${ }^{18}$

\section{Conclusion}

During the nineteenth century the US experienced remarkable demographic changes. This paper proposed to measure how immigration and technological progress may have caused them. Despite its magnitude, the impact of

\footnotetext{
$\overline{18}$ One interpretation is that, under the baseline price policy, the profit of the land improvement firm is taxed but not redistributed to households. If it were, the two experiments would yield exactly identical results.
} 


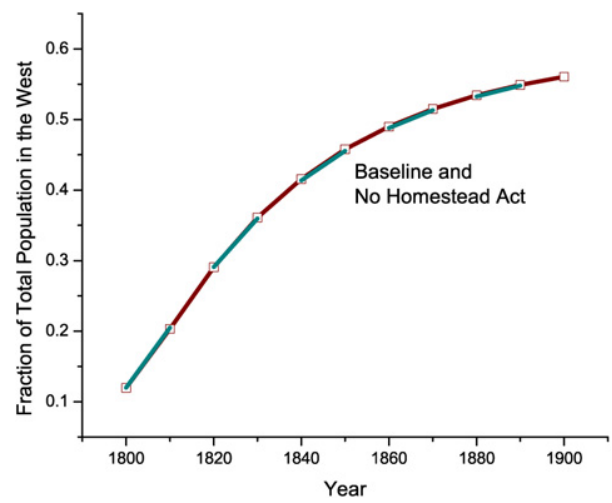

(A)

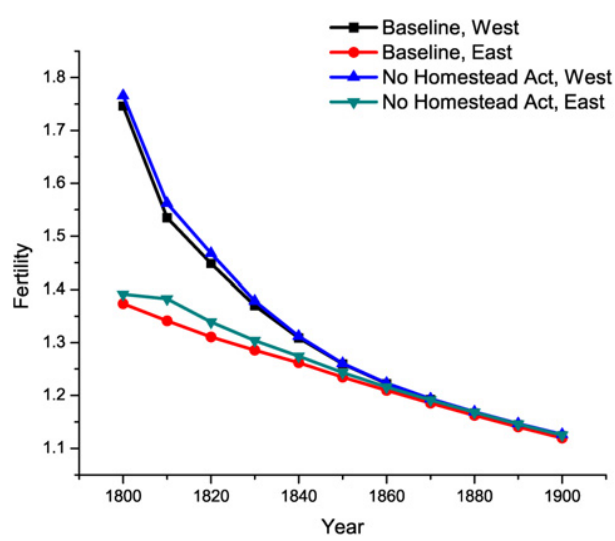

(C)

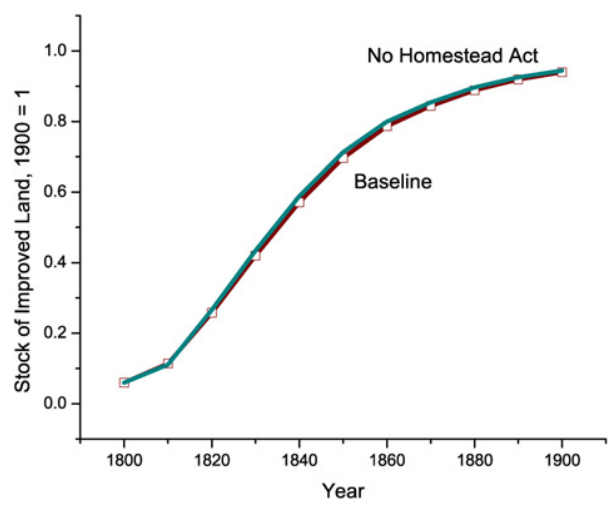

(B)

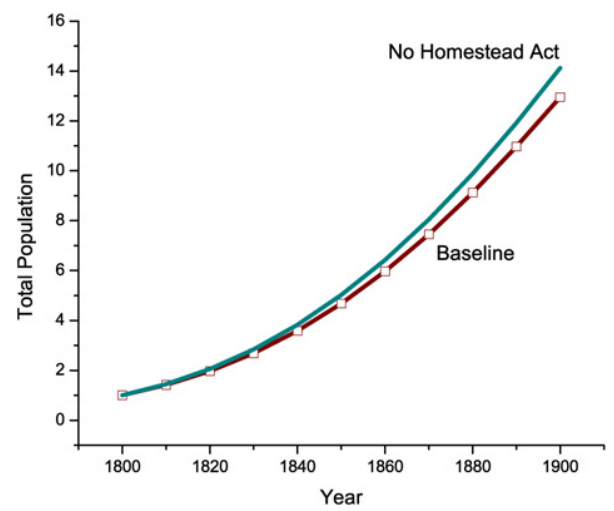

(D)

Fig. 7. Counterfactual experiment—no homestead act.

international immigration turned out to be small compared to that of technology. On the one hand, immigrants slowed down wage growth and hence promoted higher fertility inside the US. On the other hand they crowded the land which turned out to offset the increase in fertility. In the end, the rate of natural increase in the US was barely affected. Technological progress, through the transportation revolution and wage growth, had the biggest impact on the geographic distribution of population and its rate of natural increase.

\section{Acknowledgment}

I am very thankful to Jeremy Greenwood for his support and guidance. I am also indebted to two anonymous referees for useful comments. Finally, I would like to thank Mark Bils, Stanley Engerman and participants at the 2004 SED meetings in Florence.

\section{References}

Atack, J., Bateman, F., Parker, W.N., 2000, Northern agriculture and the westward movement. In: Engerman and Gallman (2000).

Benhabib, J., Rogerson, R., Wright, R., 1991. Homework in macroeconomics: Household production and aggregate fluctuations. Journal of Political Economy 99 (6), 1166-1187.

Coelho, P.R., Shepherd, J.F., 1976. Regional differences in real wages: The United States, 1851-1880. Explorations in Economic History 13 (2), 203-230.

Easterlin, R.A., 1976. Population change and farm settlement in the Northern United States. Journal of Economic History 36 (1), $45-75$.

Engerman, S.L., Gallman, R.E., 2000. The Cambridge Economic History of the United States. Cambridge Univ. Press, Cambridge.

Fishlow, A., 1965. American Railroads and the Transformation of the Ante-Bellum Economy. Harvard Univ. Press, Cambridge.

Gallaway, L.E., Vedder, R.K., 1975. Migration and the old Northwest. In: Klingaman, D.C., Vedder, R.K. (Eds.), Essays in Nineteenth Century Economic History: The Old Northwest. Ohio Univ. Press, Athens. 
Gallman, R.E., 1986. The United States Capital Stock in the Nineteenth Century. Unpublished notes.

Gallman, R.E., 1992. American economic growth before the Civil War: The testimony of the capital stock estimates. In: Gallman, R.E., Wallis, J.J.

(Eds.), American Economic Growth and Standards of Living before the Civil War. The Univ. of Chicago Press, Chicago.

Gallman, R.E., 2000. Economic Growth and Structural Change in the Long Nineteenth Century. In: Engerman and Gallman (2000).

Greenwood, J., Seshadri, A., 2002. The US demographic transition. American Economic Review 92 (2), 153-159.

Greenwood, J., Seshadri, A., Vandenbroucke, G., 2005. The baby boom and baby bust. American Economic Review 95 (1), $183-207$.

Haines, M.R., 2000. The population of the United States, 1790-1920. In: Engerman and Gallman (2000).

Herrendorf, B., Schmitz, J.A., Teixeira, A., 2006. Exploring the implications of large decreases in transportation costs. Mimeo.

Margo, R.A., 2000. Wages and Labor Markets in the United States, 1820-1860. The Univ. of Chicago Press, Chicago.

Mitchell, B.R., 1998. International Historical Statistics: The Americas, 1750-1993. Stockton Press, New York.

O'Rourke, K.H., Williamson, J.G., 1999. Globalization and History, The Evolution of a Nineteenth-Century Atlantic Economy. MIT Press, Cambridge.

Primack, M.L., 1962. Farm formed capital in American agriculture, 1850-1910. PhD thesis. University of North Carolina.

Yasuba, Y., 1962. Birth Rates of the White Population in the United States, 1800-1860, an Economic Study. Johns Hopkins University Studies in Historical and Political Science 79th ser., vol. 2. Johns Hopkins Press, Baltimore. 